\title{
Antiepileptic Treatment in Paediatric Oncology - An Interdisciplinary Challenge
}

\author{
D. Tibussek ${ }^{1}$ \\ F. Distelmaier ${ }^{1}$ \\ S. Schönberger ${ }^{2}$ \\ U. Göbel ${ }^{2}$ \\ E. Mayatepek ${ }^{1}$
}

\section{Antiepileptische Therapie in der pädiatrischen Onkologie - eine interdisziplinäre Herausforderung}

\section{Abstract}

Epileptic seizures are a common and clinically relevant problem in paediatric oncology. Attributable to the heterogeneity of this group of patients and a number of possible comorbidities antiepileptic treatment in paediatric oncology poses a number of diagnostic and therapeutic challenges. This requires a close interdisciplinary approach to the seizing child or adolescent. A prompt and detailed diagnostic work-up is needed in every case in order to establish the diagnosis and, equally important, to detect secondary aetiological factors, e.g. epileptogenic drugs or any acute underlying pathology, such as metabolic or toxic encephalopathies, CNS-infections or cerebrovascular events. This might offer the opportunity for a specific causative treatment and thus prevent unnecessary long-term antiepileptic drug (AED) treatment. If AED treatment is initiated several aspects have to be taken into account. Most importantly, AEDs and chemotherapeutic drugs (CTDs) may interact. Depending on the comedication this may result in reduced tumour or seizure control or unexpected toxicity of AEDs or CTDs. Understanding these interactions will allow to anticipate clinically relevant adverse effects. AED may be further complicated by side-effects, some of them of particular concern for children or adolescents, such as cognitive effects, myelotoxicity, serious rashes, endocrinological disturbances, and many more. Beside critically questioning the need for AED treatment it is therefore important to prefer AED with a good safety-profile in this population. Enzyme-inducing and inhibiting AED should be avoided if possible. Preliminary studies indicate that gabapentin and levetiracetam may provide

\section{Zusammenfassung}

Epileptische Anfälle stellen in der pädiatrischen Onkologie ein häufiges und klinisch relevantes Problem dar. Bedingt durch die Heterogenität der betroffenen Patientengruppe und einer Vielzahl von möglichen Komorbiditäten sind sowohl das diagnostische Vorgehen als auch die antikonvulsive Therapie eine besondere Herausforderung, die ein interdisziplinäres Vorgehen erfordert. Diagnostisch sind neben einer Vielzahl von potenziell epileptogenen Medikamenten vor allem akute Begleiterkrankungen im Verlauf der Krebstherapie zu berücksichtigen, die ursächlich für das Auftreten von Anfällen sein können. Beispiele sind metabolische oder toxische Encephalopathien, ZNS-Infektionen oder auch zerebrovaskuläre Ereignisse. Da diese zum Teil lebensbedrohlichen Erkrankungen zum Teil kausal behandelbar sind, erfordert jedes anfallsverdächtige Ereignisses eine rasche und umfassende Abklärung. So können spezifische Ursachen erkannt und behandelt sowie unnötige antikonvulsive Langzeittherapien vermieden werden. Besteht eine Therapieindikation zur antikonvulsiven Dauertherapie so liegt die Schwierigkeit primär in einer Vielzahl von Komedikationen und damit der Gefahr von Wechselwirkungen insbesondere zwischen Antikonvulsiva und Chemotherapeutika. Das Wissen um diese Wechselwirkungen ist wichtig, da sowohl die Prognose der Krebserkrankung, als auch die der Epilepsie hierdurch nennenswert beeinflusst werden kann. Zusätzlich erschweren eine Reihe onkologisch relevanter Nebenwirkungen die Entscheidungsfindung bei der Auswahl der Antiepileptika. Dies betrifft z.B. kognitive Nebenwirkungen, myelotoxische Wirkungen, Dermatosen, endokrinolo-

Affiliation

${ }^{1}$ Department of General Paediatrics, University Children's Hospital, Düsseldorf, Germany

${ }^{2}$ Clinic for Paediatric Oncology, Haematology and Immunology, University Children's Hospital, Düsseldorf,

Germany

Correspondence

Dr. Daniel Tibussek - Department of General Paediatrics · University Children's Hospital · Moorenstrasse 5 . 40225 Düsseldorf · Germany · Tel.: +49/211/8117687 - Fax: +49/211/8118757 ·

E-mail: daniel.tibussek@med.uni-duesseldorf.de

Bibliography

Klin Pädiatr 2006; 218: 340-349 @ Georg Thieme Verlag KG Stuttgart · New York

DOI 10.1055/s-2006-942257

ISSN 0300-8630 
good options in terms of efficacy and safety. However, more properly designed clinical studies are warranted to raise the level of evidence for robust clinical recommendations. Until that time, clinicians will need to continue to question current policies and adapt their daily practice to evolving scientific data.

\section{Key words}

Cancer · seizures · antiepileptic drugs · drug interaction gische Effekte und andere mehr. Neben der kritischen Indikationsstellung einer antikonvulsiven Therapie gilt es daher bevorzugt Antikonvulsiva einzusetzen, die ein günstiges Nebenwirkungsprofil in dieser Patientengruppe haben und zusätzlich durch fehlende Enzyminduktion bzw. Inhibition gekennzeichnet sind. Nach aktuellem Kenntnisstand scheinen hier vor allem Gabapentin und Levetiracetam günstige Optionen darzustellen. Angesichts einer sehr schlechten Studienlage sind jedoch weitere klinische Studien zu diesen wichtigen Fragestellungen dringend zu fordern, aktuelle Therapieregime kritisch zu hinterfragen und gegebenenfalls der aktuellen Datenlage anzupassen.

\section{Schlüsselwörter}

Krebs $\cdot$ Krampfanfälle $\cdot$ Antiepileptika $\cdot$ Wechselwirkungen

$\begin{array}{ll}\text { Abbreviations } \\ \text { AED } & \text { antiepileptic drug } \\ \text { ASP } & \text { L-asparaginase } \\ \text { BBB } & \text { blood brain barrier } \\ \text { BUS } & \text { busulfan } \\ \text { CBZ } & \text { carbamazepine } \\ \text { CIS } & \text { cisplatin } \\ \text { CSA } & \text { cyclosporine A } \\ \text { CTD } & \text { chemotherapeutic drug } \\ \text { CYP } & \text { cytochrome P 450 } \\ \text { DNET } & \text { dysembryoplastic neuroepithelial tumor } \\ \text { EIAED } & \text { enzyme-inducing anti-epileptic drugs } \\ \text { ETX } & \text { ethosuximide } \\ \text { IFO } & \text { ifosfamide } \\ \text { MTX } & \text { methotrexate } \\ \text { PBT } & \text { phenobarbital } \\ \text { PHT } & \text { phenytoin } \\ \text { TDM } & \text { therapeutic drug monitoring } \\ \text { UGT } & \text { UDP-glucoronosyltransferase } \\ \text { VPA } & \text { valproic acid }\end{array}$

\section{Introduction}

Seizures are a common complication in paediatric oncology and often significantly impact the quality of life of patients and relatives. This applies not only to children with brain tumours, where an incidence of up to $70 \%$ depending on the type of tumour has been reported [30], but also to systemic malignancies. A sizable proportion of patients with systemic cancer present with at least one seizure during the course of the disease. As an example, in children and adolescents with acute lymphoblastic leukaemia a seizure prevalence between 8 and $13 \%$ has been reported [ 45 , $52,76]$. Aetiology includes a number of possibly preventable or treatable conditions, which may be directly related to secondary effects of anti-cancer treatment. Moreover, anticonvulsive drug treatment in this particular group of patients comprises a number of difficulties, making seizures an interdisciplinary challenge. Apart from the potential for serious side effects of antiepileptic drugs (AEDs), some of them of particular concern for children, recent years have seen new appreciation of drug interactions with AEDs that are important in neoplastic disorders.
The current review aims to summarize some key aspects of anticonvulsive treatment in paediatric oncology. We also intend to critically question some current clinical policies and point out areas suitable for future interdisciplinary research in this field.

\section{Aetiology of seizures in paediatric oncology}

The exact pathophysiology of seizures during the course of malignant diseases is often multifactorial and not well understood. Seizures in patients with brain tumours are usually directly related to focal cerebral damages and effects on the surrounding non-tumoural, cerebral tissue. This may be due to the tumour itself or to anti-cancer treatment (neurosurgery, irradiation, chemotherapy). Etiological mechanisms include theories of altered peritumoural amino acids, changes in regional metabolism involving $\mathrm{pH}$, neuronal or glial enzyme and protein expression, and localized immunological changes. Distribution and function of the NMDA subclass of glutamate receptors may also play a role [3]. Certain tumours (e.g., oligodendroglioma, DNET, ganglioglioma) and tumour localisations appear to be associated with a higher seizure risk (see Table $\mathbf{1}$ and $\mathbf{2}$ ). However, there is some variation in seizure incidence even within a single histological tumour subtype. Therefore, reliable risk factors are currently difficult to define particularly in the paediatric age group, where only limited data are available [36].

Table 1 Possible risk factors for seizure occurrence in patients with brain tumours [69]

\begin{tabular}{l}
\hline possible risk factors for seizures in brain tumours \\
\hline lower-grade, slower growing tumours (epilepsy) \\
\hline higher-grade rapidly progressive tumours (seizures at presentation) \\
\hline superficial and cortical based tumours \\
\hline parietal lobe and temporal lobe tumours \\
\hline focal neurologic deficits \\
\hline multifocal tumours \\
\hline radiation therapy \\
incomplete tumour resection
\end{tabular}


Table 2 Example of seizure incidence in paediatric brain tumours (selected from reference [36])

\begin{tabular}{|lc|}
\hline tumor type & seizure incidence $(\boldsymbol{n}=\mathbf{1 5 7})$ \\
\hline low-grade astrocytoma & $19 \%$ \\
\hline malignant astrocytoma & $28 \%$ \\
\hline medulloblastoma & $8 \%$ \\
\hline ependymoma & $13 \%$ \\
\hline PNET & $25 \%$ \\
\hline choroid plexus carcinoma & $35 \%$ \\
\hline optic pathway tumour & $14 \%$ \\
\hline germ cell & $12 \%$ \\
\hline pineoblastoma & $23 \%$ \\
\hline craniopharyngeoma & $10 \%$ \\
\hline
\end{tabular}

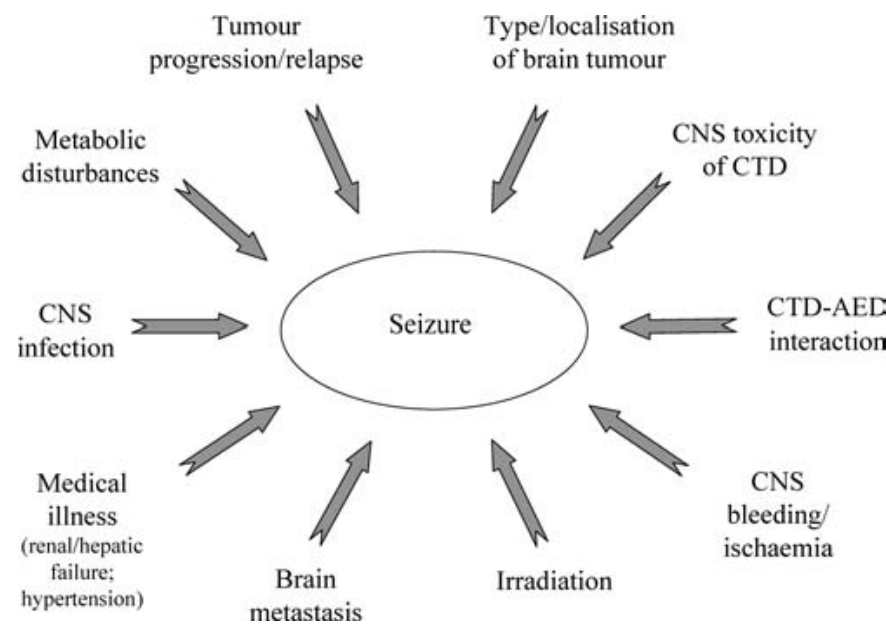

Fig. 1 Possible aetiological factors of seizures in oncological patients.

In systemic cancer the aetiology may be even more complex (see Fig. 1). Indirect effects of the cancer or its treatment such as brain metastasis or leptomeningeal disease, hypertension, fever, CNS infections, cerebral infarction or bleeding, electrolyte disturbances (hyponatraemia, hypocalaemia, hypomagnesaemia), metabolic or toxic encephalopathies are possible reasons for epileptic seizures. Chemotherapy and certain other drugs used for supportive care in oncology are epileptogenic, especially in patients with an altered blood-brain barrier (BBB) (see Table 3). These secondary effects are often associated with the type and timecourse of the underlying malignancy, type of CTD, comedications, and acute illnesses related to tumour treatment. From the clinical perspective it has to be stressed that a number of these aetiological factors are treatable and/or preventable [17].

Table 3 Cancer treatment associated with seizure occurrence (adopted from reference [55])

asparaginase, etoposide (IA), interleukin-2, busulphan (HD), erythropoietin, levamisole, BCNU, 5-Fluorouracil, mechloramine, carboplatin (IA), fludarabine, methotrexate, chorambucil (HD), GM-CSF, mitotane, cytosine arabinoside (HD or IT), hexamethylmelamine, pentostatin, dacarbazine, ifosfamide, thalidomide, interferon (IT), vinca alkaloids

HD: high-dose; IT: intra-thecal; IA: intra-arterial.

\section{Seizures related to cancer treatment}

In general, acute neurological symptoms under certain CTDs are not uncommon $[35,55,75]$. The toxicity of CTDs to the central nervous system is directly related to their ability to cross the BBB. Clinical signs suggestive of neurotoxicity are usually non-specific: altered level of consciousness, behavioural disorders and/or motor deficits. Seizures are often part of the acute presentation [53].

The diagnosis of chemotherapy-induced seizures is made clinically, and is based on the temporal relationship between drug administration and neurological complication and, equally important, knowledge of side effects of specific agents. Therefore, some clinically important CTDs associated with seizures are discussed in more detail.

\section{Methotrexate (MTX)}

MTX has the potential to cause both acute and delayed neurotoxicity, particularly after intrathecal (i.t.) or high dose intravenous (i.v.) administration [52, 58] The mechanism of MTX-related neurotoxicity is still unclear. An excess of homocystein and consecutively of excitatory neurotransmitters has been found in some children [57]. Neurotoxicity usually manifests as seizures, occurring a median of 10-11 days after i.t. MTX. The frequency of seizures or other acute CNS effects during ALL therapy in childhood has been reported at 3 to $13 \%[17,45]$. Neurotoxicity is usually self-limited and the risk of recurrence appears to be low with re-treatment [55].

\section{L-asparaginase (ASP)}

ASP has been repeatedly related to cerebrovascular complications, which may be related to deficiencies of antithrombin III, plasminogen, and fibrinogen [55]. In a recent case series Kieslich et al. [38] reported five children with neurological complications presenting with headache and seizures during the first three weeks of ASP treatment. Three patients had venous thrombosis, one presented a parenchymal haemorrhage.

A study of DiMario and Packer [17] found that almost half of the seizures occurring in children with systemic cancers were attributable to complications of ASP treatment. The epileptogenic effect of L-asparaginase may result from cleaving asparagine and glutamine into aspartic acid, ammonia, and glutamate, an excitatory amino acid.

\section{Ifosfamide (IFO)}

Encephalopathy is a known adverse effect of IFO. The pathophysiology seems to be related to intoxication with chloracetaldehyde, a metabolic product of IFO [55]. The presentation and severity varies greatly and involves a clinical spectrum ranging from subclinical electroencephalographic changes, complicated seizures to coma. Nonconvulsive status epilepticus has been described in children and adults under IFO with reduced level of consciousness $[39,56]$. Onset of symptoms may be within hours of administration without evidence of a dose-response curve. It is generally self-limiting and reversible between 48 and $72 \mathrm{~h}$ after discontinuation of IFO. However, severe and even fatal cases have been reported [20]. Therefore, as effective therapy is available especially for patients with severe symptoms of toxicity early diagnosis is essential (see Table 4; references [50, 54]. Whether re- 
Table 4 Methylene blue in IFO-encephalopathy [54]

\begin{tabular}{lll}
\hline methylene blue & usual dose (i. v.) & no. of daily doses \\
\hline therapeutic & $50 \mathrm{mg}$ & 6 (until symptoms recede) \\
\hline preventive & $50 \mathrm{mg}$ & 4 \\
\hline
\end{tabular}

administration should be performed under prophylactic treatment with methylen blue remains controversial. However, in paediatric oncology, instead of re-administration replacement of IFO by cyclophosphamide will usually be preferred.

\section{Cisplatin (CIS)}

CIS has principally been related to peripheral neurotoxicity. However, CNS disorders such as the posterior reversible encephalopathy syndrome (cortical blindness, hemiparesis, aphasia, and coma) and isolated seizures have also been reported. CIS-related seizures may start within a few hours of the last CIS exposure, and are not related to the cumulative CIS dose. Usually these effects are completely reversible. Metabolic changes (e.g. hypocalcaemia, hypomagnesaemia, and hyponatraemia) may contribute to seizure susceptibility [75].

\section{Busulfan (BUS)}

BUS is a common component of conditioning regimens for haematopoietic stem cell transplantation. It rapidly crosses the BBB. Neurotoxicity is a widely known complication of high-dose BU, with seizures occurring in up to $7.5 \%$ of children without AED prophylaxis [29]. Seizures may occur during BUS administration or within 24 hours after the last dose, but seem to rarely happen before the seventh dose $[16,29]$. It is now common practice to give anticonvulsant prophylaxis along with high-dose BUS (see below).

\section{Cyclosporine A (CSA)}

Although not a classical CTD, CSA is often part of the therapeutic regime in oncology. Neurotoxicity is one of the most significant clinical side effects of the CSA, occurring in up to $60 \%$ of transplant patients [66]. It is considered a drug with high epileptogenic potential [62]. However, the mechanism is poorly understood. There might be some interference of CSA with mitochondrial energy metabolism [66]. Neurotoxicity may occur during long-term treatment even when blood concentrations of CSA are within the therapeutic range. Single seizures, status epilepticus and development of the posterior reversible encephalopathy syndrome have frequently been published. Dose reduction or withdrawal of CSA usually results in resolution of clinical symptoms.

\section{Diagnostic approach after first seizure in paediatric oncology}

Due to the complexity and variability of the paediatric oncological population it is not possible to provide universal recommendations how to approach seizures in these children. However, some general aspects of the diagnostic work-up of a child after a first seizure have to be considered.

Firstly, the importance of the correct diagnosis before initiation of AED treatment cannot be overstated. There is a wide differen- tial diagnosis of paroxysmal events in infancy and childhood and misdiagnosis as epilepsy is common $[35,72]$ Conversely, more subtle ictal events such as confusion, sensory or autonomic symptoms might be misinterpreted as non-epileptic. Therefore, the most important help to diagnosis is the clinical history supported by detailed seizure description from a witness to the episode [9]. Further information can sometimes be obtained from an EEG. However, a normal interictal EEG does not exclude epilepsy and vice versa. The gold standard for diagnosis would be video-EEG-monitoring in order to document an ictal event. However, in clinical practice this is often not feasible. In patients with reduced consciousness a non-convulsive status epilepticus has to be strongly considered and early EEG should become a general routine in such cases, particularly under certain CTDs, such as IFO or MTX.

If a clear seizure has been documented it has to be differentiated between a single seizure, which may be situation-related, and epilepsy. Strong efforts have to be made to classify the patients seizure, or less likely in oncology, place seizures in the context of an epilepsy syndrome. Seizures may be febrile or non-febrile. They might include a single symptom or have complex symptomatology. Description of seizures should be focused on precipitating factors, the very initial ictal manifestations (aura? focal onset?), and include the whole sequence of ictal symptoms as well as postictal abnormalities. The initial symptomatology may have localising value pointing to a specific seizure onset zone [60]. Seizures may be generalised (e.g. absences, tonic-clonic, myoclonic) or partial (focal onset) with or without secondary generalisation. Classification will often be essential for indication and selection of appropriate AEDs [27]. Brain tumour-related epileptic seizures are mostly focal, although generalization is common and may occur so quickly that the focal phase remains unnoticed. Generalized seizures are more common in children with systemic malignancies. It can be assumed that most seizures in oncology will be symptomatic. However, there may be cases where a genetic seizure susceptibility is unmasked by an acute illness and/or epileptogenic drugs.

Secondly, strong efforts have to be made to identify specific secondary effects that may have lead to increased seizure susceptibility. In oncology some of these may even pose potentially lifethreatening conditions, such as CNS infections or cerebral bleedings, intoxications or metabolic encephalopathies. Importantly, causal treatment of the underlying condition may be possible in a relevant proportion of patients. Therefore, an aggressive diagnostic work-up should be initiated promptly if a seizure occurs during the course of a malignancy (see Fig. 2). Although currently not routinely performed, we propose to include detection of drug levels of CTDs and/or their toxic metabolites (blood, CSF) if possible. Toxic drug levels may be identified resulting in modification of therapy regimes. In addition, pooling these data within clinical trials may enable clinicians to better understand the pathophysiology of neurotoxicity of certain CTDs.

\section{Treatment of seizures and epilepsy in paediatric oncology}

In general, the clinical decision to initiate an AED is based on the judgement that the risk of seizure occurrence outweighs the risk 

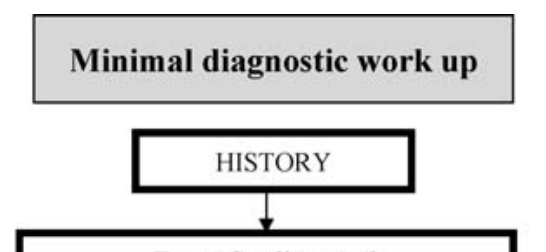

Type of malignancy? Phase of cancer treatment?

Recent change of medication? Current neutropenia?

Current acute illness? Type of seizure?
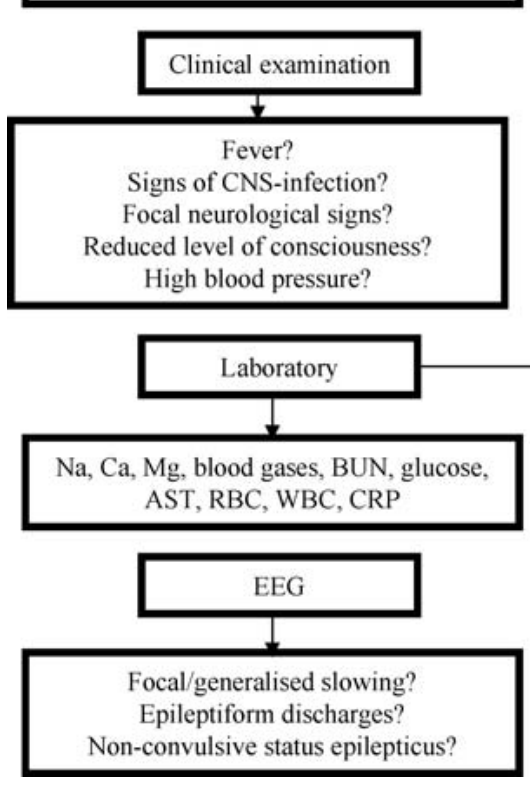

of AEDs and their possible toxic effects [21]. Predicting the risk of seizure recurrence forms another essential part of the decision for or against AED treatment. However, this may be particularly difficult in paediatric oncology. In general, seizure recurrence in children who suffered the first seizure during the intensive CTD treatment phase tends to be infrequent, usually occurring within three to six months of the first seizure. Often, AED may be discontinued shortly after the causative abnormality has been corrected, thus preventing unnecessary initiation of long-term AED treatment $[30,37]$. Options may be treatment of CNS infections, correction of electrolyte disturbances including the critical review of the current hydration regime and/or diuretic treatment, correction of blood sugar, discontinuation of potentially causal CTD, and, if available, antagonistic treatment (e.g. IFO). If a CTD is likely causal for seizure occurrence its indication, dosage, and infusion rate should be critically questioned. In addition, the patient should be immediately reported to the clinical trial office. Alternative treatment should be considered before re-exposure for those patients who developed seizures attributable to a certain CTD.

However, the recurrence risk may be significantly higher in children with fixed neurological abnormalities and certain cerebral defects [45]. In adults with brain tumours it appeared that the earlier seizures occurred in the course of illness, the more likely they are to recur [69]. Brain imaging might sometimes offer important information contributing to the treatment decision.

If initiation of AED treatment is indicated, the choice of AED in paediatric oncology is based on the classification of seizures,
Fig. 2 Suggested diagnostic work up after a seizure in the oncological child.
CTD levels

if CTDs with known

CNS toxicity

AED levels

if applicable age and sex of the patient, comorbidities, and comedications. An individualized approach is therefore required in any such case. We strongly suggest that a paediatrician with expertise in epilepsies in children should always be involved in this complex decision process, the regular review of antiepileptic management and withdrawal of treatment.

\section{Drug interactions in paediatric oncology}

A main challenge of AED treatment in paediatric oncology is the high number of comedications to be expected in the majority of patients [43, 74]. This will inevitably imply the potential for pharmacokinetic and pharmacodynamic drug interactions and it may be almost impossible to predict every pharmacological modification caused by the variety of drugs given at the same time. Pharmacokinetic drug interactions may result in changes of absorption, elimination, protein binding, or distribution of a drug. Drug metabolism accounts for most clinically relevant pharmacokinetic drug interactions between AEDs and CTDs, particularly those involving cytochrome P450 (CYP) isoenzymes in hepatic metabolism. Many of the drugs in use in paediatric oncology are metabolised by the CYP isoenzyme system and thus interactions mainly derive from inhibition or induction of these isoenzymes. The main isoenzymes in AED metabolism are CYP3A4, CYP2C9, and CYP2C19. For CTD metabolism, CYP3A4 is the most important. In addition, UDP-glucoronosyltransferase (UGT) enzymes can also play a role. The potential of enzyme induction and inhibition varies widely among AED (see Table $\mathbf{5}$ ). 
Table 5 Enzyme-inducing or inhibiting characteristics of different AED

\begin{tabular}{|lll}
\hline AED & inducer & inhibitor \\
\hline carbamazepine & yes (CYP3A4, CYP2C19, CYP2C19) & no \\
\hline clobazam & no & no \\
\hline ethosuximide & no & no \\
\hline gabapentin & no & no \\
\hline lamotrigine & yes (UGT) & no \\
\hline levetiracetam & no & no \\
\hline oxcarbazepine & yes (CYP3A4 UGT) & yes (CYP2C19) \\
\hline phenobarbital & yes (CYP3A4, CYP2C19, CYP2C19) & no \\
\hline phenytoin & yes (CYP3A4, CYP2C19, CYP2C19) & no \\
\hline pregabaline & no & no \\
\hline sulthiame & no & yes (CYP2C) \\
\hline tiagabine & no & no \\
\hline topiramate & yes (CYP3A4) & yes (CYP2C19) \\
\hline valproic acid & no & yes (CYP2C9) \\
\hline zonisamide & no & no \\
\hline
\end{tabular}

According to the systematic approach by Vecht et al. [74] the most relevant clinical consequences of drug interactions or altered pharmacodynamics, respectively, can be summarized as follows: a) reduced efficacy of antiepileptic drugs, b) reduced efficacy of CTD , c) increased toxicity of AED, d) increased toxicity of CTD.

Although only very few clinical studies have focussed on these special issues, case reports provide alarming evidence that this is by no means only a theoretical matter, but has strong impact on clinical routine and decision making. This is illustrated by some exemplary data provided by current literature.

\section{Reduced efficacy of antiepileptic drugs}

A number of case-reports of adult patients demonstrated a marked drop of phenytoin (PHT) concentrations of up to $50 \%$ after CTD administration. This was mainly attributed to cisplatin [22]. In a retrospective study by Grossmann et al. [26] all patients who received three or more cycles of cisplatin and carmustine chemotherapy for primary brain tumours required an average increase in their maintenance PHT dose of $41 \%$ to achieve therapeutic PHT levels.

Valproic acid (VPA) has also been reported to be influenced by cisplatin. In a patient receiving daily VPA, severe seizures were observed 7 weeks after the first cisplatin-based chemotherapy cycle, when the serum VPA concentration was found to be reduced by approximately $50 \%$ of the initial level [32]. Another case report described the recurrence of tonic-clonic seizure in a child with acute lymphoblastic leukaemia under VPA therapy a few hours after high-dose MTX. An acute decline of the serum VPA concentration to about $25 \%$ of the pre-MTX value could be observed [64].

\section{Reduced efficacy of CTD}

The potential of drug interactions to significantly worsen the outcome of malignant diseases under CTD was impressively illustrated by a study of Relling et al. [59]. Forty of 716 (5.6\%) conse- cutive children treated for acute lymphoblastic leukaemia received treatment for 30 days or longer with enzyme-inducing anticonvulsants (PHT, PBT, CBZ, or a combination) at the same time as antileukaemic therapy. In this study anticonvulsant therapy was significantly related to worse event-free survival with occurrence of more haematological, and CNS relapses among the 566 patients with B-lineage leukaemia. A faster clearance of teniposide and methotrexate was found among patients receiving AEDs [59].

A very recent retrospective study by Oberndorfer et al. [51] evaluated the effects of coadministration of AED on survival rates of patients with glioblastoma multiforme, who underwent surgery, radiotherapy and chemotherapy. A significant decline of survival rates in the group of patients who received enzyme-inducing AEDs (EIAED) was found.

Another clinically important example refers to data provided from Hassan et al. [29] who were first to systematically study the influence of PHT as preventative AED on BUS pharmacokinetics and pharamcodynamics in patients during conditioning prior to bone marrow transplantation using BUS. They reported a significantly faster clearance, a lower area under the concentration-time curve and a shorter half-life if the BUS regime was combined with PHT.

\section{Increased toxicity of AED}

Very little data are available on this possible effect of interaction. Fluorouracil, an inhibitor of the CPY2C9 isoezyme, has been reported to induce toxic plasma concentrations of PHT leading to severe neurological deficits mainly attributed to cerebellar disturbances (Brickel et al. 2003). It can be speculated that increased toxicity of AEDs under certain enzyme-inhibiting CTDs is underrepresented in current literature.

\section{Increased toxicity of CTD}

VPA is a potent inhibitor of the CYP isoenzymes, mainly of CYP2C9. As VPA has very recently been studied as an adjunctive therapy for acute myeloid leukaemia and myelodysplastic syndrome [10], interactions with certain CTDs might become more relevant in future. In a follow-up study of 70 adults with high-grade gliomas an association of VPA with a fotemustine-cisplatin regimen resulted in a three-fold higher incidence of reversible thrombopenia, neutropenia or both. Haematological side-effects decreased after AED modification during the continued chemotherapy [7].

Increased toxicity of IFO has been reported in a paediatric patient who received PBT as comedication. He developed IFO-encephalopathy, which was attributed to the enzyme inducing activity of PBT leading to a higher amount of toxic IFO-metabolites [23].

\section{Corticosteroids und AED}

Interactions between corticosteroids and PHT and/or PBT may be almost unpredictable. A variety of effects have been observed. PHT and PBT have the potential to shorten the half-life and increase total body clearance of dexamethasone and prednisone [11]. On the other hand, both increased and lowered levels of PHT were seen under comedication with dexamethasone. Lackner [40] reported a patient receiving dexamethasone who required a daily PHT dose of greater than $10 \mathrm{mg} / \mathrm{kg}$ to maintain 
therapeutic serum concentration. The concentration increased by nearly $300 \%$ after dexamethasone was discontinued. Contrary, Lawson et al. [42] reported increased levels of PHT in patients receiving PHT and dexamethasone. This may be attributed to competition on protein binding leading to intoxications, which also might mimic tumour progression. It has been hypothesized that decreased levels may be caused by induction of hepatic metabolism causing a loss of seizure control [61]. However, the real pathophysiology of these contradictory effects is poorly understood.

Summarizing these results it can be stated that drug interactions between AEDs and CTDs can have substantial effects on clinical outcome. We therefore propose that therapeutic drug monitoring may contribute to improving cancer chemotherapy and should therefore be further investigated particularly in view of a variety of possible drug interactions between AEDs and CTDs.

\section{Adverse effects of AED relevant in paediatric oncology}

Newer and more aggressive treatments of malignancies in childhood have lead to significantly longer survival rates of affected children. Therefore, adverse effects of long-term anticonvulsive treatment have to be considered. It is beyond the scope of this review to cover all these aspects of AED treatment in detail. A summary of the most relevant side effects of frequently used AED in paediatrics is given in Table $\mathbf{6}$. Some aspects are of special relevance in paediatric oncology.
AED related haematological side effects are particularly unwanted in paediatric oncology. Although the overall incidence in non-oncological patients seems to be low [6], it has been reported that, when AEDs are used in combination with antineoplastic agents, these effects can be pronounced [7]. Aplastic anaemia (CBZ, PBT, PHT, ETX) and thrombopenia (VPA) are most commonly reported.

Serious rashes, including Stevens-Johnson syndrome and anticonvulsant hypersensitivity syndrome are rare, but potentially fatal adverse effects that can occur and are more common when certain AEDs (PHT, PBT, CBZ) are used in combination with irradiation therapy [47].

One of the most severe long-term sequelae of childhood cancer treatment may be neurocognitive disorders [4]. In this context CNS side-effects of AEDs are particularly worrying. No AED appears to be completely exempt from unfavourable cognitive and/or behavioural effects [2]. Previous clinical studies indicate that older AEDs have the most negative cognitive profile, mainly PB and PHT [18, 49]. However, even the "new" AEDs, e. g., topiramate or levetiracetam, have been associated with adverse cognitive or neurobehavioral effects. Lamotrigine seems to have a favourable cognitive profile $[1,46,67]$.

Appetite regulation can be a relevant clinical problem in oncology in both terms, uncontrolled eating, mainly in cerebral malignancies or anorexia, either due to CTDs or the malignancy itself. These effects may be worsen by certain AED (see Table 6 ).

Table 6 Commonly prescribed AED in childhood, dosage, side-effects [2, 5, 13, 27]

\begin{tabular}{|c|c|c|c|c|c|}
\hline AED & $\begin{array}{l}\text { usual oral dosage mg/ } \\
\text { kg per day }\end{array}$ & $\begin{array}{l}\text { neurobehavioral/cognitive } \\
\text { changes }\end{array}$ & weight changes & $\begin{array}{l}\text { inducing estrogen } \\
\text { metabolism }\end{array}$ & further important/serious side-effects \\
\hline carbamazepine & $10-20$ & + (memory impairment) & weight gain & ++ & $\begin{array}{l}\text { rash, aplastic anaemia (rare), ataxia, } \\
\text { diplopia }\end{array}$ \\
\hline clobazam & $0.5-1$ & + (sedation) & weight neutral & - & $\begin{array}{l}\text { hypersecretion, development } \\
\text { of tolerance }\end{array}$ \\
\hline ethosuximide & $20-30$ & rare (psychosis) & weight loss & - & aplastic anaemia (rare), rash, hiccups \\
\hline gabapentin & $23-35$ & + (behavioral problems) & weight gain & - & \\
\hline lamotrigine & $\begin{array}{l}\text { slow titration depending } \\
\text { on comedication* }\end{array}$ & \pm (Insomnia) & weight neutral & + & $\begin{array}{l}\text { rash, including Stevens-Johnsons } \\
\text { syndrome, diplopia, ataxia }\end{array}$ \\
\hline levetiracetam & $20-40$ & $\begin{array}{l}\text { + (behavioral problems; } \\
\text { psychotic events) }\end{array}$ & weight loss? & - & salivary hypersecretion \\
\hline oxcarbazepine & $30-45$ & - & weight gain & + & hyponatriaemia, rash, ataxia \\
\hline phenobarbital & $2-5$ & $\begin{array}{l}++ \text { (cognitive and sedative } \\
\text { effects) }\end{array}$ & weight neutral & ++ & aplastic anaemia \\
\hline phenytoin & $\begin{array}{l}8-10<3 \text { years } \\
4-7>3 \text { years }\end{array}$ & $\begin{array}{l}++(\text { cognitive and sedative } \\
\text { effects) }\end{array}$ & weight neutral & ++ & $\begin{array}{l}\text { aplastic anaemia, cerebellar toxicity, } \\
\text { cardiac arrythmia, purple glove syn- } \\
\text { drome }\end{array}$ \\
\hline sulthiame & $5-15$ & rare (psychotic events) & weight loss & - & ataxia, paresthesia, tachypnoea \\
\hline topiramate & slow titration: $4-6$ & + (language impairment) & weight loss & + & $\begin{array}{l}\text { nephrolithiasis, glaucoma, hypohydro- } \\
\text { sis, metabolic acidosis }\end{array}$ \\
\hline valproic acid & $15-40$ & \pm (hyperactivity) & weight gain & - & $\begin{array}{l}\text { thrombopenia, hepatic failure, hyper- } \\
\text { ammonemia, pancreatic failure, tre- } \\
\text { mor }\end{array}$ \\
\hline zonisamide & $4-12$ & ++ (psychiatric disorders) & weight loss & - & rash, ataxia, hypohydrosis \\
\hline
\end{tabular}

* add-on enzyme-inducers: 5-15 mg/kg; add-on VPA: $1-3 \mathrm{mg} / \mathrm{kg}$ 
Effects of long-term AED treatment on hormonal function, contraception, sexuality, and pregnancy is an important issue for adolescents [33]. Early counselling on effective contraception is essential in female teenagers with cancer in order to prevent unwanted pregnancies particularly in view of potentially teratogenic and mutagenic drugs during cancer treatment [41]. The influence of AED selection on current or future choices of contraceptive methods needs to be considered when choosing an AED for those patients who are likely to continue treatment into their childbearing years. Nonenzyme-inducing AEDs do not show any interactions with the oral contraceptive pill and should therefore be preferred in these patients $[14,78]$. Reduced fertility in women with epilepsy and foetal damages due to AEDs used during pregnancy are additional concerns [71].

\section{Choice of AED in paediatric oncology}

The primary concern of AED treatment is maintaining adequate seizure control. Although exact epidemiological data are missing it can be presumed that the majority of seizures in paediatric oncology will be partial or secondary generalized. A variety of older and newer AED have been shown good effectiveness in children with focal epilepsy [27]. However, the use of enzyme-inducing AED as drugs of first choice is still wide routine in paediatric oncology departments, mainly PHT, PBT, and CBZ. VPA has also been recommended [30]. However, having in mind the above described potentially fatal effects of drug interactions between AED and CTD it seems reasonable to propose that AEDs not inducing or inhibiting the cytochrome P450 system should be preferred. As rapid titration is often required, gabapentin or levetiracetam have been suggested as possible candidates with good efficacy and a favourable safety profile [34, 36, 74]. Gabapentin has been proven effective in partial seizures [19]. There is some experience that gabapentin is well tolerated and provide effective seizure control in children under CTD [36]. Levetiracetam is considered as a wide-spectrum AED effective in both partial and generalized seizures $[19,63]$. In adults with end stage brain tumours levetiracetam has been reported as a good option due to its efficacy and tolerability [34]. In children with treatment-resistant partial seizures it was effective and well tolerated as adjunctive therapy [25].

However, it has to be stressed that recommendations of longterm AED treatment in the oncology patient are not supported by robust empirical evidence. In addition, due to the complexity of patients under cancer treatment an individualized approach to any such child with epilepsy is required. According to the specific patients needs different AED treatment regimes may be indicated, including enzyme-inducing AED or combination therapy. Therefore, the right choice of treatment requires considerable expertise in the care of paediatric epilepsy patients.

If only short-term use is expected, clonazepan may be a candidate with an excellent broad-spectrum efficacy. Its use is sometimes limited by sedating effects, hypersalivation, ataxia, and most importantly, the development of tolerance, usually after 3-6 months.

Short-term use of PHT, PB or VPA may be justified if i.v.-application is necessary. However, closed monitoring of drug levels of
CTDs and AEDs is essential. If possible, therapy should rapidly be changed to non-enzyme inducing or inhibiting AED once the patient's status has stabilized. It needs to be stressed that this may again lead to significant alterations of CTD levels.

Patients with progressive tumours or severe mucositis might lose the ability to swallow even suspensions. Beside i.v.- and i.m.preparations (e.g. PB; [34]), buccal application might be considered on this occasion. This is an option for lorazepam and midazolam. Sedative side-effects of these AED may even be desirable. In addition, lorazepam has antiemetic and anxiolytic properties.

As mentioned above, epilepsy treatment in female teenagers pose a number of additional difficulties. Treatment decisions should follow currently existing guidelines for the management of epilepsy in women (e.g. [14]).

Different regimens have been suggested as preventative AED treatment in patients undergoing high-dose busulfan therapy (see Table 7). PHT should no longer be used for its potential for drug interaction and a unfavourable profile of adverse effects [29].

Last but not least it is noteworthy to mention that especially in brain tumour patients seizures may be refractory to medical management and epilepsy surgery can sometimes be performed [69].

\section{Seizure prophylaxis in children with brain tumours}

Because a substantial number of patients with brain tumours may develop seizures, it remains common practice among neurooncologists and neurosurgeons to initiate preventive AED treatment even in the absence of seizures. Many patients who have experienced a single seizure attributable to brain tumours will be put on regular AED and often keep on taking their anticonvulsive medication for years. The rational for this policy has been addressed in several studies, but continues to be controversial [68]. However, growing evidence clearly points against the usefulness of preventive AED treatment. A practice parameter established by the American Academy of Neurology [24] recommended that prophylactic anticonvulsants should not be used routinely in patients with newly diagnosed brain tumours. Perioperative prophylaxis should be tapered off after the first postoperative week. In support of this view, two recent meta-analyses found no evidence to support AED prophylaxis with PBT, PHT, or valproic acid in patients with brain tumours and no history of seizures, regardless of neoplastic type [68,70]. However, currently available data need to be interpreted with some caution. None of the studies included in

Table 7 Busulfan and options of preventive AED treatment

\begin{tabular}{lll}
\hline AED & dosage & reference \\
\hline clonazepan & $\begin{array}{l}0.1 \mathrm{mg} / \mathrm{kg} / \mathrm{d} \text { as a continous } \\
\text { i.v. infusion }\end{array}$ & Vassal et al. 1990 [73] \\
\hline clobazam & $\begin{array}{l}0.05 \mathrm{mg} / \mathrm{kg} \text { twice a day by } \\
\text { mouth }\end{array}$ & Schwarer et al. 1995 [65] \\
lorazepam & $\begin{array}{l}0.02 \text { (infants <2 yrs)-0.05 mg/ } \\
\mathrm{kg} \text { i.v. or p. o. every } 6 \mathrm{~h}\end{array}$ & Chan et al. 2002 [12] \\
\hline
\end{tabular}


meta-analyses were performed using newer AED. Moreover, there is a lack of reliable risk-factors predictive for seizure occurrence in children with cerebral tumours.

In addition, it needs to be stressed, that once a patient experiences a seizure clearly attributable to a brain tumor, long-term treatment with AED is generally accepted as proper medical care due to the high risk of recurrence [69].

\section{Conclusion}

Antiepileptic treatment in paediatric oncology poses numerous diagnostic and therapeutic challenges. This requires a close interdisciplinary approach to the seizing child or adolescent. A prompt and detailed diagnostic work-up is needed in every single case in order to establish the diagnosis and, equally important, to detect any treatable underlying pathology.

If clinical events are not clearly defined as seizures the best way to prevent adverse effects of AEDs is to consider not to give AED at all. Preventive AED treatment in patients with primary brain tumours cannot be recommended.

If AED treatment is initiated possible drug interactions and side effects relevant in paediatric oncology have to be taken into account. Enzyme inducing and inhibiting AEDs should be avoided unless alternative treatment with non-inducing AEDs is not feasible. Regular review of the continuing need for AED treatment is always required.

Regarding the new non-enzyme inducing or inhibiting AEDs, preliminary studies indicate that gabapentin and levetiracetam may provide a favourable profile in terms of efficacy and safety.

However, more properly designed clinical studies are warranted to raise the level of evidence for robust clinical recommendations. These studies should also investigate the influence of AED treatment on overall outcome measures. We believe that competence networks will be helpful to structure clinical trials and standardize future therapy regimes [15]. Clinicians will need to continue to question current policies and adapt their daily practice to evolving scientific data.

\section{Disclosure of conflicts of interest}

The authors have no conflict of interest to disclose.

\section{References}

${ }^{1}$ Aldenkamp AP, De Krom M, Reijs R. Newer antiepileptic drugs and cognitive issues. Epilepsia 2003; 44 (Suppl 4): 21 - 29

${ }^{2}$ Arzimanoglou A, Guerrini R, Aicardi J. Aicardi's Epilepsy in Children. $3^{\text {rd }}$ edn. Lippincott Williams \& Wilkins, Philadelphia 2004; 369

${ }^{3}$ Beaumont A, Whittle IR. The pathogenesis of tumor associated epilepsy. Acta Neurochir 2000; 142: 1 - 15

${ }^{4}$ Bhatia S. Cancer survivorship - pediatric issues. Hematology (Am Soc Hematol Educ Program) 2005; 1: 507-515
${ }^{5}$ Biton V. Effect of antiepileptic drugs on bodyweight: overview and clinical implications for the treatment of epilepsy. CNS Drugs 2003; 17: $781-791$

${ }^{6}$ Blackburn SC, Oliart AD, Garcia Rodriguez LA, Perez Gutthann S. Antiepileptics and blood dyscrasias: a cohort study. Pharmacotherapy 1998; 18: $1277-1283$

${ }^{7}$ Bourg V, Lebrun C, Chichmanian RM, Thomas P, Frenay M. Nitrosourea-cisplatin-based chemotherapy associated with valproate: increase of haematologic toxicity. Ann Oncol 2001; 12: 217-219

${ }^{8}$ Brickell K, Porter D, Thompson P. Phenytoin toxicity due to fluoropyrimidines (5FU/capecitabine): three case reports. Br J Cancer 2003; 89: $615-616$

${ }^{9}$ Brodie MJ, French JA. Management of epilepsy in adolescents and adults. Lancet 2000; 356: $323-329$

${ }^{10}$ Bug G, Ritter M, Wassmann B, Schoch C et al. Clinical trial of valproic acid and all-trans retinoic acid in patients with poor-risk acute myeloid leukemia. Cancer 2005; 104: 2717-2725

${ }^{11}$ Chalk JB, Ridgeway K, Brophy T, Yelland JD, Eadie MJ. Phenytoin impairs the bioavailability of dexamethasone in neurological and neurosurgical patients. J Neurol Neurosurg Psychiatry 1984; 47: 1087-1090

${ }^{12}$ Chan KW, Mullen CA, Worth LL, Choroszy M, Koontz S, Tran H, Slopis J. Lorazepam for seizure prophylaxis during high-dose busulfan administration. Bone Marrow Transplant 2002; 29: 963 - 965

${ }^{13}$ Crawford P. Interactions between antiepileptic drugs and hormonal contraception. CNS Drugs 2002; 16: 263-272

${ }^{14}$ Crawford P. Best practice guidelines for the management of women with epilepsy. Epilepsia 2005; 46 (Suppl 9): 117-124

${ }^{15}$ Creutzig U, Hannemann J, Kramer I, Zimmermann M, Herold R, Marx JF. The "quality house pediatric oncology" as an instrument for improving the performance of the trial centers. Klin Padiatr 2005; 217: $114-119$

${ }^{16}$ De La Camara R, Tomas JF, Figuera A, Berberana M, Fernandez-Ranada JM. High dose busulfan and seizures. Bone Marrow Transplant 1991; 7: $363-364$

17 DiMario FJ, Packer RJ. Acute mental status changes in children with systemic cancer. Pediatrics 1990; 85: $353-360$

18 Farwell JR, Lee YJ, Hirtz DG et al. Phenobarbital for febrile seizures effects on in telligence and on seizure recurrence. N Engl J Med 1990; 322: $364-369$

${ }^{19}$ French JA, Kanner AM, Bautista J, Abou-Khalil B, Browne T, Harden CL, Theodore WH, Bazil C, Stern J, Schachter SC, Bergen D, Hirtz D, Montouris GD, Nespeca M, Gidal B, Marks Jr WJ, Turk WR, Fischer JH, Bourgeois B, Wilner A, Faught Jr RE, Sachdeo RC, Beydoun A, Glauser TA. Efficacy and tolerability of the new antiepileptic drugs I: treatment of new onset epilepsy: report of the Therapeutics and Technology Assessment Subcommittee and Quality Standards Subcommittee of the American Academy of Neurology and the American Epilepsy Society. Neurology 2004; 62: 1252 - 1260

${ }^{20}$ Gieron MA, Barak LS, Estrada J. Severe encephalopathy associated with ifosfamide administration in two children with metastatic tumors. J Neurooncol 1988; 6: 29-30

${ }^{21}$ Gilliam FG, Fessler AJ, Baker G, Vahle V, Carter J, Attarian H. Systematic screening allows reduction of adverse antiepileptic drug effects. Neurology 2004; 62: $23-27$

22 Ghosh C, Lazarus HM, Hewlett JS, Creger RJ. Fluctuation of serum PHT concentrations during autologous bone marrow transplant for primary central nervous system tumors. J Neurooncol 1992; 12: 25-32

${ }^{23}$ Ghosn M, Carde P, Leclerq B, Flamant F, Friedman S, Droz JP, Hayat M. Ifosfamide/mesna related encephalopathy: a case report with a possible role of phenobarbital in enhancing neurotoxicity. Bull Cancer 1988; 75: $391-392$

${ }^{24}$ Glantz MJ, Cole BF, Forsyth PA, Recht LD, Wen PY, Chamberlain MC, Grossman SA, Cairncross JG. Practice parameter: anticonvulsant prophylaxis in patients with newly diagnosed brain tumors: report of the Quality Standards Subcommittee of the American Academy of Neurology. Neurology 2000; 54: 1886-1893

${ }^{25}$ Glauser TA, Ayala R, Elterman RD, Mitchell WG, Van Orman CB, Gauer LJ, Lu Z. Double-blind placebo-controlled trial of adjunctive levetiracetam in pediatric partial seizures. Neurology 2006; 66: 1654-1660

${ }^{26}$ Grossman SA, Sheidler VR, Gilbert MR. Decreased phenytoin levels in patients receiving chemotherapy. Am J Med 1989; 87: 505- 510

27 Guerrini R. Epilepsy in children. Lancet 2006; 367: 499-524

${ }^{28}$ Hartmann O. Ifosfamide induced encephalopathy: 15 observations. Arch Pediatr 2006; 13: 140-145 
${ }^{29}$ Hassan M, Oberg G, Bjorkholm M, Wallin I, Lindgren M. Influence of prophylactic anticonvulsant therapy on high-dose busulphan kinetics. Cancer Chemother Pharmacol 1993; 33: 181-186

${ }^{30}$ Hildebrand J. Management of epileptic seizures. Curr Opin Oncol 2004; 16: $314-317$

${ }^{31}$ Hindley D, Ali A, Robson C. Diagnoses made in a secondary care "fits, faints, and funny turns" clinic. Arch Dis Child 2006; 91: 214-218

32 Ikeda H, Murakami T, Takano M, Usui T, Kihira K. Pharmacokinetic interaction on valproic acid and recurrence of epileptic seizures during chemotherapy in an epileptic patient. Br J Clin Pharmacol 2005; 59: $593-597$

${ }^{33}$ Isojarvi JI. Reproductive dysfunction in women with epilepsy. Neurology 2003; 61 (6 Suppl 2): S27-S34

${ }^{34}$ Junck L. Supportive management in neuro-oncology: opportunities for patient care, teaching, and research. Curr Opin Neurol 2004; 17: $649-653$

${ }^{35}$ Keime-Guibert F, Napolitano M, Delattre JY. Neurological complications of radiotherapy and chemotherapy. J Neurol 1998; 245: 695708

${ }^{36}$ Khan RB, Hunt DL, Boop FA, Sanford RA, Merchant TE, Gajjar A, Kun LE. Seizures in children with primary brain tumors: incidence and longterm outcome. Epilepsy Res 2005; 64: 85-91

${ }^{37}$ Khan RB, Onar A. Seizure Recurrence and Risk Factors after Antiepilepsy Drug Withdrawal in Children with Brain Tumors. Epilepsia 2006; 47: 375-379

38 Kieslich M, Porto L, Lanfermann H, Jacobi G, Schwabe D, Bohles HJ. Cerebrovascular complications of L-asparaginase in the therapy of acute lymphoblastic leukemia. Pediatr Hematol Oncol 2003; 25: $484-487$

${ }^{39}$ Kilickap S, Cakar M, Onal IK, Tufan A, Akoglu H, Aksoy S, Erman M, Tekuzman G. Nonconvulsive Status Epilepticus Due to Ifosfamide. Ann Pharmacother 2006; 40: $332-335$

${ }^{40}$ Lackner TE. Interaction of dexamethasone with phenytoin. Pharmacotherapy $1991 ; 11: 344-347$

${ }^{41}$ Laurence V, Gbolade BA, Morgan SJ, Glaser A. Contraception for teenagers and young adults with cancer. Eur J Cancer 2002; 40: 2705 2716

42 Lawson LA, Blouin RA, Smith RB, Rapp RP, Young AB. Phenytoin-dexamethasone interaction: a previously unreported observation. Surg Neurol 1981; 16: $23-24$

${ }^{43}$ Langebrake C, Uhlenbrock S, Ritter J, Groll AH. Drug interactions of antimicrobial agents in children with cancer. Klin Padiatr 2005; 217 (Suppl 1): S165-S174

44 Loring DW, Meador KJ. Cognitive side effects of antiepileptic drugs in children. Neurology 2004; 62: 872-877

${ }^{45}$ Maytal J, Grossman R, Yusuf FH, Shende AC, Karayalycin G, Lanzkowsky P, Schaul N, Eviatar L. Prognosis and treatment of seizures in children with acute lymphoblastic leukemia. Epilepsia 1995; 36: 831 836

${ }^{46}$ Meador KJ, Loring DW, Vahle VJ, Ray PG, Werz MA, Fessler AJ, Ogrocki P, Schoenberg MR, Miller JM, Kustra RP. Cognitive and behavioral effects of lamotrigine and topiramate in healthy volunteers. Neurology 2005; 64: $2108-2114$

${ }^{47}$ Micali G, Linthicum K, Han N, West DP. Increased risk of erythema multiforme major with combination anticonvulsant and radiation therapies. Pharmacotherapy 1999; 19: $223-227$

48 Mockenhaupt M, Messenheimer J, Tennis P, Schlingmann J. Risk of Stevens-Johnson syndrome and toxic epidermal necrolysis in new users of antiepileptics. Neurology 2005; 64: 1134-1138

${ }^{49}$ Ney GC, Lantos G, Barr WB, Schaul N. Cerebellar atrophy in patients with long term PHT exposure and epilepsy. Arch Neurol 1994; 51: $767-771$

${ }^{50}$ Nicolao P, Giometto B. Neurological toxicity of ifosfamide. Oncology 2003; 65 (Suppl 2): $11-16$

51 Oberndorfer S, Piribauer M, Marosi C, Lahrmann H, Hitzenberger P, Grisold W. P450 enzyme inducing and non-enzyme inducing antiepileptics in glioblastoma patients treated with standard chemotherapy. J Neurooncol 2005; 72: 255-260

52 Ochs JJ, Bowman WP, Pui C-H et al. Seizures in childhood lymphoblastic leukemia patients. Lancet 1984; 2: 1422-1424

${ }^{53}$ Orbach D, Brisse H, Doz F. Central neurological manifestations during chemotherapy in children. Arch Pediatr 2003; 10: 533-539
${ }^{54}$ Pelgrims J, De Vos F, Van den Brande J, Schrijvers D, Prove A, Vermorken JB. Methylene blue in the treatment and prevention of ifosfamideinduced encephalopathy: report of 12 cases and a review of the literature. Br J Cancer 2000; 82: 291 - 294

55 Plotkin SR, Wen PY. Neurologic complications of cancer therapy. Neurol Clin 2003; 21: 279-318

${ }^{56}$ Primavera A, Audenino D, Cocito L. Ifosfamide encephalopathy and nonconvulsive status epilepticus. Can J Neurol Sci 2002; 29: 180-183

57 Quinn CT, Griener JC, Bottiglieri T, Hyland K, Farrow A, Kamen BA. Elevation of homocysteine and excitatory amino acid neurotransmitters in the CSF of children who receive methotrexate for treatment of cancer. J Clin Oncol 1997; 15: 2800-2806

58 Quinn CT, Griener JC, Bottiglieri T, Hyland K, Farrow A, Kamen BA. Methotrexate, homocysteine and seizures. J Clin Oncol 1998; 16: $393-394$

${ }^{59}$ Relling MV, Pui CH, Sandlund JT, Rivera GK, Hancock ML, Boyett JM, Schuetz EG, Evans WE. Adverse effect of anticonvulsants on efficacy of chemotherapy for acute lymphoblastic leukaemia. Lancet 2000; 356: $285-290$

${ }^{60}$ Rosenow F, Hamer HM, Knake S, Katsarou N, Fritsch B, Oertel WH, Shiratori K, Luders HO. Lateralizing and localizing signs and symptoms of epileptic seizures: significance and application in clinical practice. Nervenarzt 2001; 72: $743-749$

${ }^{61}$ Rüegg S. Dexamethasone/phenytoin interactions: neurooncological concerns. Swiss Med Wkly 2002; 132: 425-426

62 Ruffmann C, Bogliun G, Beghi E. Epileptogenic drugs: a systematic review. Expert Rev Neurother 2006; 6: 575-589

63 Sankar R. Initial treatment of epilepsy with antiepileptic drugs: pediatric issues. Neurology 2004; 63 (Suppl 4): S30-S39

${ }^{64}$ Schroder H, Ostergaard JR. Interference of high-dose methotrexate in the metabolism of valproate? Pediatr Hematol Oncol 1994; 11: 445449

${ }^{65}$ Schwarer AP, Opat SS, Watson AL, Cole-Sinclair MF. Clobazam for seizure prophylaxis during busulfan chemotherapy. Lancet 1995; 346 : 1238

${ }^{66}$ Serkova NJ, Christians U, Benet LZ. Biochemical mechanisms of cyclosporine neurotoxicity. Mol Interv 2004; 4: 97-107

${ }^{67}$ Siemes H, Brandl U, Helmstadter C, Kurlemann G, Rating D, Salke-Kellermann RA, Stephani U, Uberall M, Wiemer-Kruel A, Bergmann L. Optimizing epilepsy therapy in children and adolescents with lamotrigine. Klin Padiatr 2005; 217: 222 - 229

68 Sirven JL, Wingerchuk DM, Drazkowski JF, Lyons MK, Zimmerman RS. Seizure Prophylaxis in Patients With Brain Tumors: A Meta-analysis. Mayo Clin Proc 2004; 79: 1489-1494

${ }^{69}$ Sperling MR, Ko J. Seizures and brain tumors. Semin Oncol 2006; 33: $333-341$

${ }^{70}$ Stevens GH. Antiepileptic therapy in patients with central nervous system malignancies. Curr Neurol Neurosci Rep 2006; 6: 311 - 318

71 Tomson T, Perucca E, Battino D. Navigating toward fetal and maternal health: the challenge of treating epilepsy in pregnancy. Epilepsia 2004; 45: $1171-1175$

72 Uldall P, Alving J, Hansen LK, Kibaek M, Buchholt J. The misdiagnosis of epilepsy in children admitted to a tertiary epilepsy centre with paroxysmal events. Arch Dis Child 2006; 91: 219-221

${ }^{73}$ Vassal G, Deroussent A, Hartmann O, Challine D, Benhamou E, Valteau-Couanet D, Brugieres L, Kalifa C, Gouyette A, Lemerle J. Dose-dependent neurotoxicity of high-dose busulfan in children: a clinical and pharmacological study. Cancer Res 1990; 50: 6203-6207

74 Vecht CJ, Wagner GL, Wilms EB. Interactions between antiepileptic and chemotherapeutic drugs. Lancet Neurol 2003; 2: 404-409

75 Verstappen CC, Heimans JJ, Hoekman K, Postma TJ. Neurotoxic complications of chemotherapy in patients with cancer: clinical signs and optimal management. Drugs 2003; 63: 1549-1563

${ }^{76}$ Winick NJ, Bowman WP, Kamen BA, Roach ES, Rollins N, Jacaruso D, Buchanan GR. Unexpected acute neurologic toxicity in the treatment of children with acute lymphoblastic leukemia. J Natl Cancer Inst 1992; 84: $252-256$

77 Wong DD, Longenecker RG, Liepman M, Baker S, LaVergne M. Phenytoin-dexamethasone: a possible drug-drug interaction. JAMA 1985; 254: $2062-2063$

${ }^{78}$ Zupanc ML. Antiepileptic drugs and hormonal contraceptives in adolescent women with epilepsy. Neurology 2006; 66 (Suppl 3): S37S45 